Trechnology

\section{Evolution of Electronic Communications to Transfer Agricultural Weather Information}

\author{
Katharine B. Perry ${ }^{1}$, Rodger R. Getz ${ }^{2}$, and \\ H. Ray Kimsey, Jr. ${ }^{3}$
}

Additional index words. meteorology, extension, weather forecasts, computer

Summary. Access to weather information for planning and implementing horticultural practices is an important component of the production system for growers. Advances in meteorological instrumentation, data acquisition and storage, and communications technologies have improved greatly the potential for applying sophisticated weather information into daily on-farm decisionmaking. The North Carolina Agricultural Weather Program seeks to provide weather information to the horticultural interests of the state. It has developed over the past 13 years. Recently, budget reductions near $50 \%$ and the loss of two-thirds of the extension full-time equivalents have necessitated significant changes. Through regional cooperation and the use of electronic communications technology, the program has sustained these negative impacts and emerged as an improved program. This paper describes the evolution of a state agricultural weather program into what is now a regional cooperative project to provide the weather information horticultural producers require.

$\mathrm{W}$

eather is a significant factor in horticultural production systems. Access to weather information for planning and implementing horticultural practices is an important component for growers (Carlson,

${ }^{1}$ Professor and Specialist-in-Charge, Department of Horticultural Science,, North Carolina State University, Box 7609, Raleigh, NC 27695-7609.

${ }^{2}$ Meteorologist-in-Charge, Southeast Agricultural Weather Service Center, Auburn, AL 36831-3267.

${ }^{3}$ Applications Development Project Supervisor, Extension Computer Services, North Carolina State University, Box 7641, Raleigh, NC 27695-7641.
1989; Getz, 1978; Johnson and Perry, 1983; Seeley and Graham, 1987; Vining et al., 1984; Weiss and Robb, 1986). Some of the information required by horticultural producers is not available in the forecasts for the general public for their safety and property protection. In addition, access to an "up-through-yesterday" database is essential for the application of models to predict crop, disease, and insect growth and development (Hanks and Ritchie, 1991; Hodges, 1991; Stewart and Nielsen, 1990). The transfer of these models from the research community to agricultural industry has been very slow. A major obstacle has been the lack of an accessible and dependable source of the meteorological data required to run these models. Required parameters in addition to air temperature and precipitation often include radiation, atmospheric moisture, soil temperature and moisture, and wind speed and direction. Evaporation and wetness periods also are sometimes required. Advances in meteorological instrumentation, data acquisition and storage, and communications technologies have improved greatly the potential to move these models into operational applications (Dahlgren, 1991; Meyer and Hubbard, 1992; Senft, 1993; Wright and Ley, 1989). In general, there is a need for more-specific forecasts of agricultural parameters. These forecasts need to be on a more finely resolved time and space scale. This paper describes the evolution of a state agricultural weather program into what is now a regional cooperative project to provide the weather information horticultural producers require.

The North Carolina Agricultural Weather Program (AWP) was initiated in 1980 with two full-time extension specialist positions. An agricultural weather advisory program was developed using the National Weather Service (NWS) Agricultural Weather Service Center (AWSC) located in Auburn, Ala., as a model. From Apr. 1980 through Nov. 1991, an agricultural weather advisory was issued twice a day, 5 days a week. The advisories were a compilation of several NWS products (some not available to the public) and other derived parameters. When its issuance was terminated in 1991, the advisory included a table of forecast values and a portion of text describing the upcoming weather.

Related activities of the AWP were the weekly summary of temperature and precipitation for the North Carolina Weather and Crops Bulletin produced by the North Carolina Dept. of Agriculture-Agricultural Statistics Division and the Weekly Weather and Crops Bulletin produced jointly by the U.S. Dept. of Commerce and the USDA. Educational programs about agricultural meteorology, the advisories, and other weather information also were implemented. In Jan. 1982, one extension specialist position was changed to $50 \%$ extension and 50\% research. This reduced the extension component of the AWP to 1.5 full-time equivalents (FTE), but did enhance the overall program by the addition of the research component.

To support the advisory service and the data summaries, a significant amount of time was committed to routinely collecting and archiving data. Many of the data came from networks operated by other agencies; e.g., NWS Cooperative Weather Observers and Hydrology Network. In addition, the AWP oversaw an extension volunteer network of daily weather observers to add significant agricultural data.

Many of the developments during the 12 years from 
AGRICULTURAL MEATHER GUIDANCE FOR ASHEVILLE, NC WATIONAL WEATHER SERVICE

SE AGRICULTURAL WEATHER SERVICE CENTER, AUBURN, AL

Morning forecast made at 4:20 AM on Tue Mar 16, 1993

Day length $=11: 57$ / Sunrise at $6: 41$ AM / Sunset at $6: 38$ PM EST

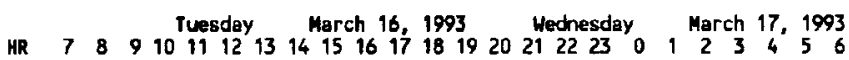

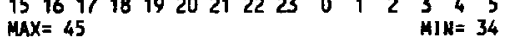

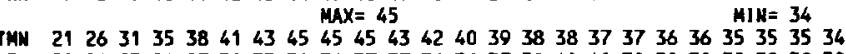
I3H $20 \begin{array}{llllllllllllllllllllllllll}21 & 24 & 27 & 30 & 33 & 34 & 36 & 37 & 37 & 36 & 36 & 37 & 39 & 40 & 40 & 39 & 39 & 39 & 39 & 39 & 39 & 38\end{array}$ $\begin{array}{lllllllllllllllllllllllll}034 & 17 & 18 & 18 & 19 & 20 & 20 & 21 & 23 & 24 & 26 & 27 & 28 & 29 & 29 & 30 & 30 & 29 & 29 & 28 & 28 & 29 & 29 & 30 & 30\end{array}$

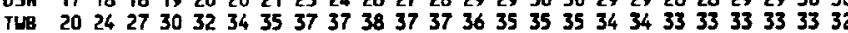

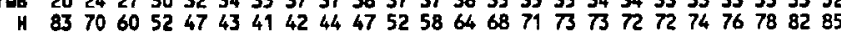

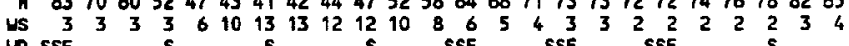

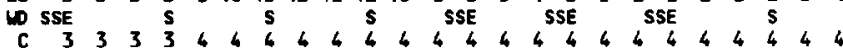

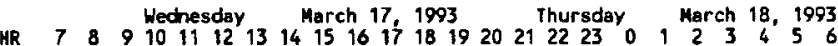

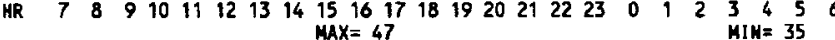
IMN $35374042 \quad 4345464747474543 \quad 4241403938383837 \quad$ MIN $=36 \quad 36 \quad 35$

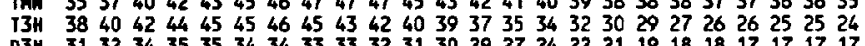

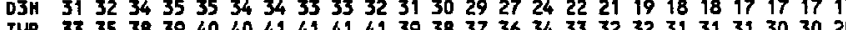
THB $33 \quad 3538394040414141141393837 \quad 363433 \quad 32 \quad 32 \quad 3131 \quad 3130 \quad 3029$ N $86827977 \quad 7166 \quad 62595756 \quad 575960 \quad 57 \quad 54504947 \quad 4545 \quad 45 \quad 4546 \quad 47$

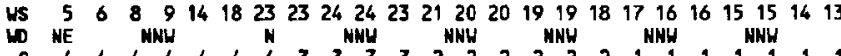

WHERE: $H R=$ tine (ESI) $13=1 \mathrm{PH}$

WHERE: $\begin{aligned} \text { HR } & =\text { tine (ESI) } 13=1 P M \\ \text { TMM } & =\text { air temp based on forecast MAX/MIN temps \& diurnal temp curve }\end{aligned}$

TMN = air temp based on forecast MAX/MIN tem

T3H = air temp based on WHS Jhr temp curve

DSH = deupoint tenp based on Mus 3hr temp eurve

TWB = estinated wet bulb temps using TMN \& D3H values

$H=$ Z relative humidity using TAM \& D3H values

US = wind speed (knots) interpolated from WWS $3 \mathrm{hr}$ fcst

$W=$ wind direction from Whs $3 h r$ fcsts $(C=$ calm)

$=$ sky condition interpolated from WWS $6 \mathrm{hr}$ fests 1 CLR, 2 SCT, 3 BXN, 4 OVC

Fig. 1. Sample agricultural weather product for Asheville, N.C.

1980 to 1991 were linked directly to advances in communications technology. The AWP's information delivery system started with a paper tape punch teletype to transmit advisories to the NWS. Data were received via facsimile machines and summarized with hand-held calculators. These tools were replaced with a desktop computer and information then was transmitted via modem over telephone lines. In addition, the incorporation of a satellite receiver allowed much of the weather information to be brought directly into the original database system.

Dissemination of the advisories to users also developed over the years. Originally, they were broadcast over the National Oceanic and Atmospheric Administration Weather Radio Network, which does not reach several agricultural areas of the state. Advisories were sent by means of a teletype circuit connecting radio and television stations that, in turn, broadcast the advisories. Later, the advisories were made part of the Teletip system, Extension's toll-free telephone message request system. NCDA's Market Newsline, a teletext system transmitted on a television side band similar to the closed caption for the hearing-impaired system, also broadcast the advisories for a few years. When the Extension electronic news and mail system, CAROLINE, was implemented in 1988, the advisories and other weather information products were posted daily on that system and made available to campus and county extension personnel.

The AWP experienced pivotal changes during 1991. In April of that year, the responsibility for the North Carolina Agricultural Research Service Automatic Weather Station Network and Database (NCWX) was moved to the AWP. AWP efforts focused on replacement of the existing data acquisition equipment and improvement of data accessibility. The AWP was, however, affected by the resignation of one of the specialists and the subsequent loss of this open position due to staff downsizing made necessary by budget constraints.
Therefore, the decision was made to terminate the advisory in its current form and replace it with automated products. These automated products would provide forecasts ofweather parameters required for agricultural operations, with particular emphasis on parameters for operational crop, pest, and disease models. The goal was to provide a 7-day forecast of maximum and minimum air temperatures and a 2-day forecast of dewpoint, wind speed, wind direction, and the livestock weather safety index. Subsequent work was to address the addition of soil temperature, evaporation, and solar radiation forecasts. This was to be accomplished by developing software to retrieve the meteorological forecast information for these parameters and use it as input to programs that would produce the desired agricultural weather information.

The National Weather Service forecast information had become available in 1991 via the National Research and Education Network (NREN), also known as Internet (Krol, 1992). This was a very important development, because it freed the AWP from the expensive leasing of the satellite receiver and the associated equipment, supplies, and software required for obtaining the information.

While the software development was underway, the opportunity arose to cooperate with the Auburn AWSC. The AWSC agreed to use North Carolina climate data and the NWS information to produce: 4-day forecast of hourly air temperature, wetbulb, dewpoint, relative humidity, wind speed and direction, and sky conditions (Fig. 1); 4-day forecast of critically low-temperature-threshold duration (Fig. 2); and a 2-day forecast of dew dry-off time, drying potential, evaporation, and lowest relative humidity (Fig. 3 ). Products to be added are: precipitation probabilities and

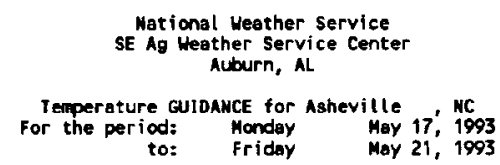
Produced at 4:50 MH CDT on Mon 05/17/93 using an model output.

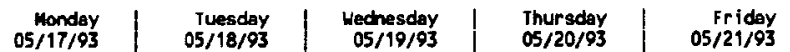
IN $80+4|56+4 \quad 77+1| 57+5$
$87+1 \mid 48-4$

WHERE: MIN = Minimun tenperature (normally occurs near sunrise)

MXX = Meximum temperature (normally occurs at mid afternoon)

DFW = Departure from normal temperature

Hourly temperature estimates for Asheville

BEGIN MOUR LOCAL TIME (EDT) $13=19 \%$

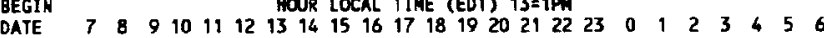

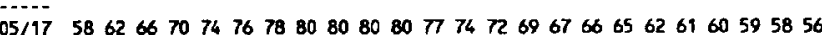

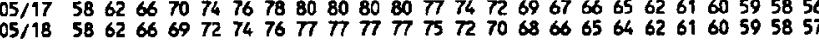

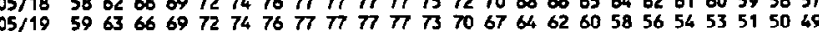

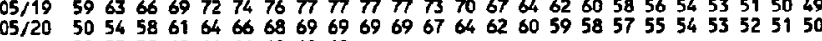
$05 / 2152555962 \quad 6466 \quad 686969$

WHERE: BEGIN DATE = starting manth/day of the 24 hour period

NOTE: Estimates besed on diurnal temperature curve and should be used on nights then radiational conditions (light winds) are expected.

Estimated temperature durations(houre) for Ashoville

Date for the 24 hour periods ending HON locel time of the indicated day

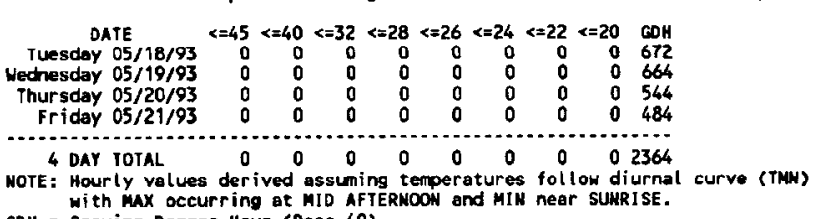

with MAX occurring at MID AFTERNOON and MIN near SUMRISE.

GOH = Growing Degree Hour (Base 40)

Fig. 2. Sample temperature forecast for Asheville, N.C. 


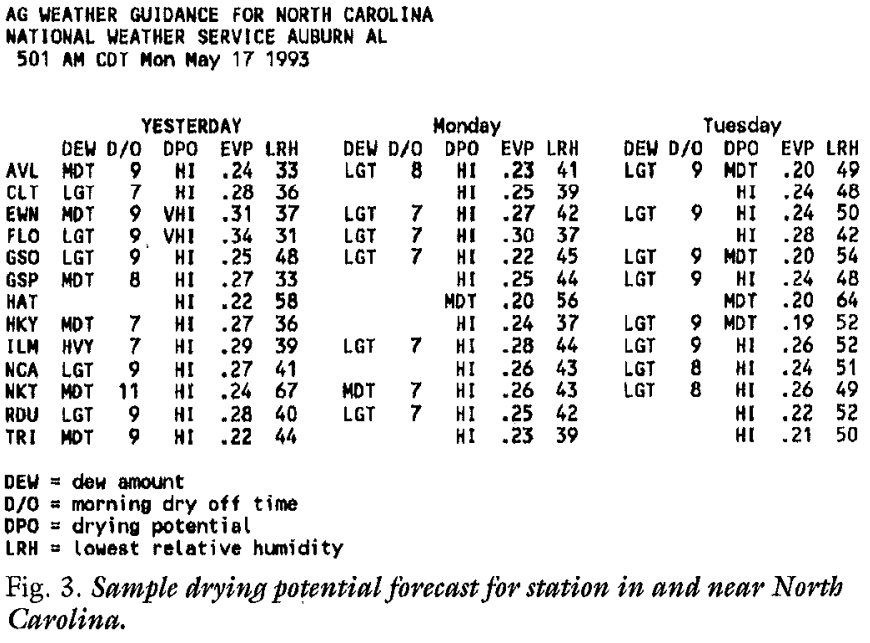

amounts for 5 days; a 6- to 10-day outlook for maximum and minimum air temperatures and precipitation; a 2-day forecast of hours of sunshine and total solar radiation; and a 5-day forecast of daily growing degree-day values for numerous base temperatures. Both temporal (hourly values vs. daily and for 7 vs. 5 days) and spatial coverage have been greatly improved over the previous advisory product.

The agricultural weather information can be retrieved in the following four ways: 1) gopher software (developed at the Univ. of Minnesota), 2) anonymous file transfer protocol (ftp), 3) almanac retrieval software (developed at Oregon State Univ.), and 4) electronic mail. The gopher method of retrieval is a convenient method for North Carolina State Univ. campus personnel or other university campus personnel. Weather products may be viewed, printed, transferred to a local computer, or mailed electronically. The second option, ftp, is a method that can be automated easily for retrieval of one or more weather products on a daily basis. This method also requires that the user's computer be connected to NREN.

The third and fourth methods allow county extension personnel access to the agricultural weather data even though their computers are not attached to the NREN. The third method, almanac, is useful for retrieving occasional files when needed. An electronic message is sent by the requester to the almanac server. The requested report then is returned to the requester automatically. The final method, electronic mail list, is for the person who wishes to receive daily weather products. The requester subscribes to an electronic mail list for the desired weather product. After subscribing to the appropriate mail list, the weather product is mailed electronically to the subscriber each day. Future plans include malting these products available directly to growers through other mechanisms. Two potential methods for direct-to-grower dissemination are a modem-accessible electronic bulletin board and a "fax-back" system. A fax-back system allows anyone with a fax machine to request certain products be faxed to them.
Asignificant educational requirement also exists. Growers need educational training to know what products are available, how to receive them, how to interpret them, and how to apply them in their daily decisionmaking process. They need to understand the strengths and weaknesses of the varying forecast components. For example, growers often overlook the need to update the weather information they are using constantly. They need to know how to access and make the best possible use of all the weather information that can be made available for them.

The AWP continues to evolve. It has met several potentially devastating obstacles and managed to survive and improve. The new products provide users with numerous application opportunities in today's high-technology world of agriculture.

\section{Literature Cited}

Carlson, J.D. 1989. The importance of agricultural weather information: a Michigan survey. Bul. Amer. Met. Soc. 70:366-380.

Dahlgren, J. 1991. Oklahoma Mesonet benefits all. Agr. at OSU 21(3):5-7.

Getz, R.R. 1978. A survey of New Jersey's agricultural weather service users. Bul. Amer. Met. Soc. 59:1297-1304.

Hanks, J. and J.T. Ritchie. 1991. Modeling plant and soil systems. Amer. Soc. Agron., Madison, Wis, Agron. Ser. 31.

Hodges, T. 1991. Predicting crop phenology. CRC Press, Boca Raton, Fla.

Johnson, G.L. and K.B. Perry. 1983. Broadcasters' use of agricultural weather products: A North Carolina survey. Bul. Amer. Met. Soc. 64:1026-1028.

Krol, E. 1992. The whole Internet--user's guide and catalog. O'Reilly and Associates, Sebastopol, Calif.

Meyer, S.J. and K.G. Hubbard. 1992. Nonfederal automated weather stations and networks in the United States and Canada: A preliminary survey. Bul. Amer. Met. Soc. 73:449-457.

Seeley, M.W. and J.M. Graham. 1987. The importance and utilization of agricultural weather information in Minnesota: A survey. In: Amer. Meteor. Soc., 18th Conf. on Agr. and For. Met. Preprints, p. $80-82$.

Senft, D. 1993. Weather network helps protect crops, cut irrigation. Agr. Res. 41(4):22.

Stewart, B.A. and D.R. Nielsen. 1990. Irrigation of agricultural crops. Amer. Soc. Agron., Madison, Wis., Agron. Ser. 30.

Vining, K.C., C.A. Pope, III, and W.A. Dugas, Jr. 1984. Usefulness of weather information to Texas agricultural producers. Bul. Amer. Met. Soc. 65:1316-1319.

Weiss, A. and J.G. Robb. 1986. Results and interpretations from a survey on agriculturally related weather information. Bul. Amer. Met. Soc. 67:10-15.

Wright, M.A. and T.W. Ley. 1989. Washington public agricultural weather system user manual. EB1547 Washington State Univ. Coop. Ext., Pullman. 